\title{
Quartz crystal microbalance monitoring of large-area graphene anodization reveals layer fracturing
}

\author{
Anastasia Svetlova $^{1,2}$ (1) Guillermo Beltramo ${ }^{3} \cdot$ Dmitry Kireev $^{1,4,5} \cdot$ Andreas Offenhäusser $^{1,2}$
}

Received: 22 February 2021 / Accepted: 26 March 2021 / Published online: 13 April 2021

(c) The Author(s) 2021

\begin{abstract}
Graphene has numerous potential applications in ultrathin electronics. There an electrode should function in contact with fluids and under mechanical stress; therefore, its stability is specifically of concern. Here, we explored a custom-made quartz crystal microbalance (QCM) sensor covered with wet-transferred large-scale monolayer graphene for investigation of an electrode behavior. Monolayer graphene was found to be stable on an oscillating substrate in contact with air and liquid. Under the liquid flow and simultaneously applied electrochemical potential, we managed to induce graphene oxidation, impact of which was observed on a quartz crystal microbalance monitoring and Raman spectra. Applied potentials of $1 \mathrm{~V}$ and higher (vs. $\mathrm{Ag} / \mathrm{AgCl}$ reference electrode) caused graphene oxidation which led to loss of the layer integrity and erosion of the material.
\end{abstract}

\section{Introduction}

Graphene is one of the most intensely studied materials due to its' unique electrical properties [1,2]. However, a practical implementation of graphene-based electronics for monitoring of biological systems still faces several obstacles. One of the challenges is an inert and highly hydrophobic surface of graphene that leaves only few routes for its functionalization [3, 4], for example, interactions of pi-pi stacking with selective molecules [5] or aromatic fragments of proteins [6]. Several other routes exist that increase surface compliance come at a price of a partial loss of an electronic

Anastasia Svetlova

mothperson86@yandex.ru

$\triangle$ Dmitry Kireev

kirdmitry@gmail.com

1 Institute of Biological Information Processing IBI-3, Forschungszentrum Jülich GmbH, Wilhelm-Johnen Straße, 52425 Jülich, Germany

2 RWTH Aachen University, 52062 Aachen, Germany

3 Institute of Biological Information Processing IBI-2, Forschungszentrum Jülich GmbH, Wilhelm-Johnen Straße, 52425 Jülich, Germany

4 Department of Electrical and Computer Engineering, The University of Texas at Austin, Austin, TX 78758, USA

5 Microelectronics Research Center, The University of Texas, Austin, TX 78758, USA properties. Treatments with oxygen plasma, deep UV, or ozone $[7,8]$ increase surface hydrophilicity by introducing evenly distributed oxygen-containing functional groups on the surface that can be further utilized for covalent reactions [9].

Another possible route to create similar functional groups would be an electrochemically controlled anodization of graphene [10]. Our research provides insight on this process carried out with chemical vapor deposition (CVD)-grown monolayer graphene. Quartz crystal microbalance with dissipation monitoring (QCM-D) is largely employed for investigation of surface properties of variety of conventional conductive and dielectric materials, as well as their interactions with aqueous environments. Monitoring of an oscillation energy dissipation provides additional insights about a layer structure. Objective of the current work is to investigate large-scale CVD graphene layer anodization using custom-made graphene/ $\mathrm{SiO}_{2} \mathrm{QCM}$ sensors and Raman spectra mapping.

\section{Experimental details}

CVD graphene was purchased from Graphenea, Spain. The graphene/copper foil was coated with $200 \mathrm{~nm}$ thick layer of PMMA, placed in $0.1 \mathrm{M}$ ammonium persulfate solution. After complete etching of the metal, the graphene/PMMA stack is fished and transferred to a Milli-Q water for removal 
of residual by-products. After that, it is fished on top of a QCM sensor, dried overnight at room temperature, and annealed at $160{ }^{\circ} \mathrm{C}$ for $1 \mathrm{~h}$. Finally, PMMA is removed by washing in hot acetone. $\mathrm{SiO}_{2}$-coated QCM sensors were purchased from QSense, Sweden.

Cyclic voltammetry and amperometry were performed with a BioLogic potentiostat (BioLogic, France) that was connected to a microfluidic chamber with an electrochemistry microfluidic module on a QCM-D setup from QSense. An electrochemistry module consists of a working electrode (QCM sensor surface), a platinum counter electrode, and an $\mathrm{Ag} / \mathrm{AgCl}$ reference electrode (Dri-Ref, World Precision Instruments, USA).

Confocal Raman microscopy was performed using an alpha300R setup (WITec, Germany). Illumination of the sample is performed using a $532 \mathrm{~nm}$ excitation line from a single-mode frequency-doubled Nd:YAG laser via a $100-\mu \mathrm{m}$ single-mode glass fiber. A Zeiss LD EC Epiplan-Neofluar $50 \mathrm{x} / 0.55$ objective and the laser power at the sample behind the objective that is $0.3 \mathrm{~mW}$ to avoid the damage of the sample were used. An edge filter was used to separate the Raman signal from the excitation line. Confocality of the Raman signal was achieved via a $50 \mu \mathrm{m}$ multi-mode fiberglass between the microscope and the Raman spectrometer, where the fiber serves as a pin-hole. The Raman spectrometer was equipped with a holographic grating of 600 lines/ $\mathrm{mm}$. As a detector, a Newton Andor EMCCD camera with $1600 \times 200$ pixels was used. With this configuration, a spectral resolution of about $2 \mathrm{~cm}^{-1}$ was obtained. All datasets were analyzed using cluster analysis and non-negative matrix factorization.

\section{Results and discussion}

\section{Sensor fabrication and evaluation of deposited CVD graphene}

A QCM sensor consists of a polished quartz crystal sandwiched between two gold electrodes. An alternating potential applied between the electrodes results in oscillations of a crystal. Under certain potential, a crystal oscillations reach resonance, creating a standing wave. Upper electrode is coated with materials, thus, creating a surface that is facing a solution. Deposition of layers on a sensor surface results in shifts of the resonance frequency, allowing sensitivity of ng/ $\mathrm{cm}^{2}$ in an experiment [11]. Scheme of $\mathrm{SiO}_{2}$ sensor layers with a transferred CVD graphene layer is shown in Fig. 1.

Prior to graphene deposition, fundamental frequencies of $\mathrm{SiO}_{2}$-coated sensors were recorded in air 3 times at $21{ }^{\circ} \mathrm{C}$ for each sensor to account for changes caused by different mounting stresses from a QCM measurement chamber. A sensor is placed in a chamber for a measurement and

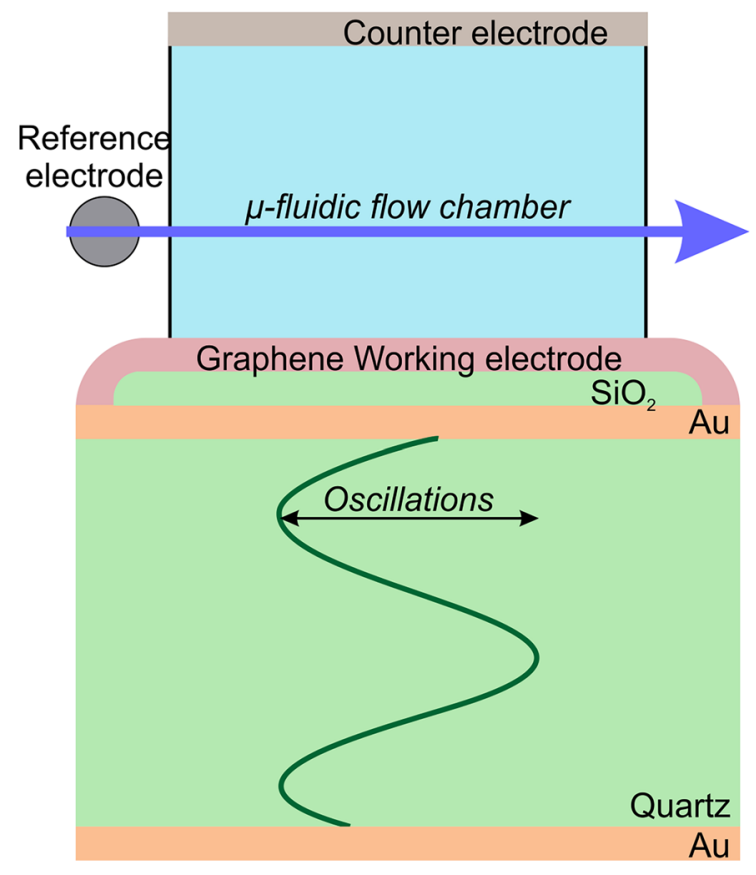

Fig. 1 A cross section of layers of a custom-made sensor after graphene deposition and positioning in a chamber. Not to scale. Ti and $\mathrm{Cr}$ adhesion layers on Au-quartz and $\mathrm{Au}-\mathrm{SiO}_{2}$ interfaces are not depicted

stabilized for some time to achieve an equilibrium of temperature and adsorbed layers until changes are below $0.1 \mathrm{~Hz}$ in $10 \mathrm{~min}$. Same procedure is repeated for sensors after graphene deposition and decrease in recorded resonance frequencies implies deposition of material. Total changes in normalized 13th resonance frequency are shown in Table 1. For Sensor 1 , a decrease in $f_{13}$ was $-54 \pm 13 \mathrm{~Hz}$ and for Sensor 2: $-85 \pm 6 \mathrm{~Hz}$. $\Delta m$ is recalculated based on these values and Sauerbrey equation:

$\Delta m=-C_{\mathrm{QCM}} \frac{\Delta f_{n}}{n}$,

where $C_{\mathrm{QCM}}$ is the mass sensitivity constant $\left(17.7 \mathrm{ng} \mathrm{cm}^{-2}\right.$ $\mathrm{Hz}^{-1}$ for quartz), $\Delta f_{n}$ is the absolute change in the resonance frequency, $n$ is the overtone number, $\Delta f_{n} / n$ is the normalized frequency change.

After that a surface area of an ideal monolayer graphene that would correspond to this mass is estimated using a theoretical value $0.76 \mathrm{mg} / \mathrm{m}^{2}$ for mass density of an ideal monolayer graphene. This theoretical value comes from known atomic distances in a graphitic lattice and a mass of a carbon atom.

Observed mass changes correspond to a surface area bigger than a total area of a sensor $\left(1.54 \mathrm{~cm}^{2}\right)$. By dividing an estimated surface area by a sensor area, and it was determined that a mass corresponding to $\sim 13$ and 20 layers of 
Table 1 Monitoring of a large-scale CVD graphene deposition on $\mathrm{SiO}_{2}$ QCM sensors

\begin{tabular}{lllll}
$\Delta f_{13}$ normalized, $\mathrm{Hz}$ & $\Delta m, \mu \mathrm{g}$ & $\begin{array}{l}\text { Surface area of graphene, } \mathrm{cm}^{2} \text { (if an } \\
\text { ideal monolayer is assumed) }\end{array}$ & $\begin{array}{l}\text { Number of ideal } \\
\text { monolayers }\end{array}$ & $\begin{array}{l}\text { Average of CVD graphene } \\
\text { layer thickness on the sensor, } \\
\text { nm }\end{array}$ \\
\hline$-54 \pm 13$ & 1.49 & 19.6 & 12.8 & 4.02 \\
$-85 \pm 6$ & 2.33 & 30.7 & 20.0 & 6.70 \\
\hline
\end{tabular}

ideal monolayer graphene was deposited on sensors. These findings match up to a previous report [12] where deposited CVD graphene layers were removed from QCM sensors with oxygen plasma with continuous monitoring in the process. Authors also indicate 14-19.7 multilayering of graphene calculated from QCM resonance frequencies changes. High numbers of estimated layers can be accounted to several reasons. First of all, it was demonstrated that wet transfer results in wrinkles in a layer and folds of a sheet [13-15] and both of these features would increase measured mass. Second, water molecules that can be trapped between a graphene layer and a surface $[16,17]$ resulting in an increased mass. At last, molecularly thin PMMA residues that remain on the surface of graphene after annealing [18] can also contribute to overall mass increase.

Stability of sensors in a QCM experiment was tested in air and in liquid. Sensors were left for extended period of time without a liquid in a chamber, and changes were monitored. After initial segment of equilibration to the set temperature resonance frequencies remained stable with a small drift of $\sim 0.5 \mathrm{~Hz} / \mathrm{h}$ that may arise from uneven pressure from the chamber and is insignificant for the duration of a regular experiment that takes $1-2 \mathrm{~h}$. The same behavior was observed for sensors in contact with liquid (Milli-Q water) in a chamber. The absence of frequency shifts during the equilibration indicates that graphene layers are stable on $\mathrm{SiO}_{2}$ surface despite oscillations of a surface that occur during the measurement.

\section{Monitoring of graphene layer under applied potentials}

To determine electrochemically active surface area, cyclic voltammetry with $1,1^{\prime}-$ Ferrocenedimethanol $(0.6 \mathrm{mM}$ in $100 \mathrm{mM} \mathrm{KCl}$ ) was conducted. Linear potential sweep with a scan rate $1 \mathrm{~V} / \mathrm{s}$ was applied in a potential interval $(-0.2$; + 0.6) $\mathrm{V}$ vs $\mathrm{Ag} / \mathrm{AgCl}$. During this part of characterization, no rapid changes in frequency or dissipation were revealed.

The layers were pre-treated by linear voltage sweeps with scan rate $10 \mathrm{mV} / \mathrm{s}$ in potential range $(-1 ;+1) \mathrm{V}(\mathrm{vs} \mathrm{Ag} /$
Fig. 2 QCM monitoring of an electrochemical treatment. a Normalized frequency (blue, left axis) and dissipation (orange, right axis) during 2 cycles of linear voltage sweeps $(10 \mathrm{mV} / \mathrm{s})$ in range $(-1 ;+1) \mathrm{V}$ vs $\mathrm{Ag} / \mathrm{AgCl}$. Gray bars indicate time when applied potential reaches +1 V. b Cyclic voltammogram of $1,1^{\prime}$-Ferrocenedimethanol before application of $+1 \mathrm{~V}$ potentials (green) and after (orange), scan rate $500 \mathrm{mV} / \mathrm{s}$. c Normalized frequency (blue, left axis) and dissipation (orange, right axis) during application of voltage pulses, description in text. d Electrochemical current recorded on graphene electrode for $0.1-1.1 \mathrm{~V}$ vs $\mathrm{Ag} / \mathrm{AgCl}$ voltage pulses
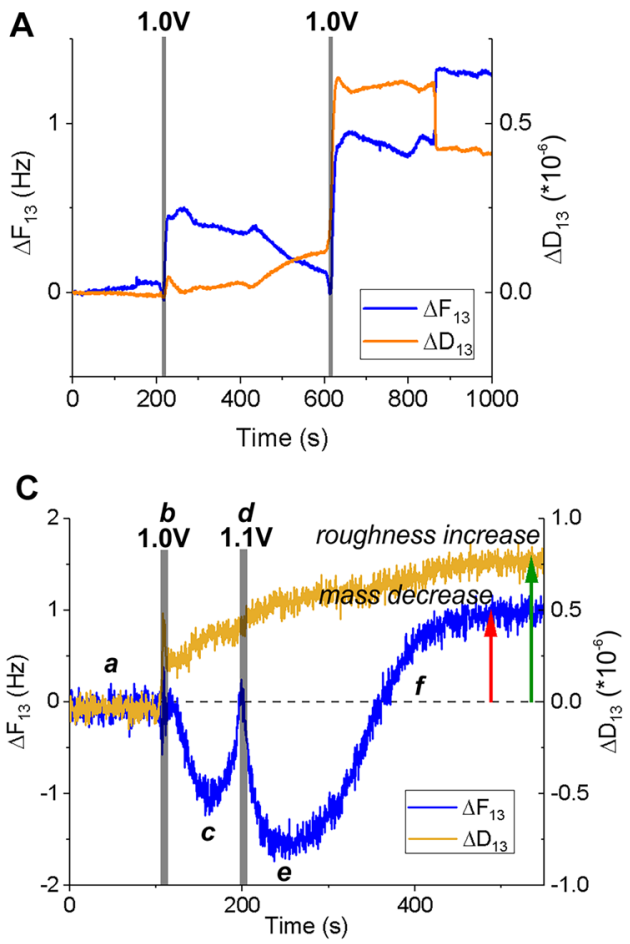

B

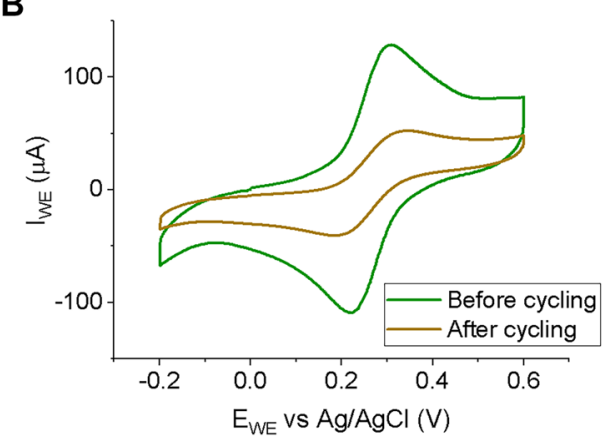

D

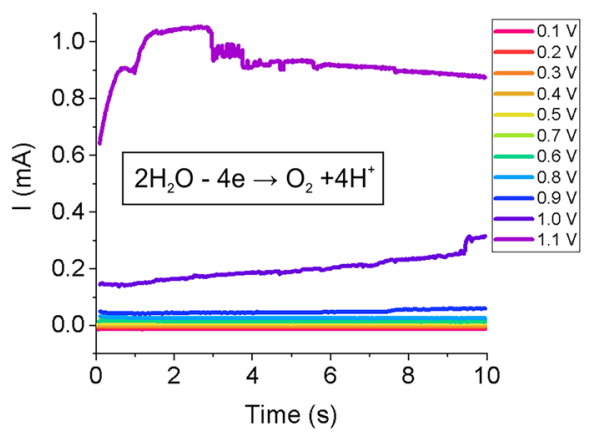


$\mathrm{AgCl})$. In Fig. $2 \mathrm{a}$, changes in frequency, $\Delta f_{13}$, and dissipation, $\Delta D_{13}$, for 13 th overtone are represented. We observed abrupt shifts at times when applied potential values reached $+1 \mathrm{~V}$ ( $\mathrm{vs} \mathrm{Ag} / \mathrm{AgCl})$. After this treatment, oxidative and reductive currents of the probe decreased (Fig. 2b), despite an expectation that anodization of an electrode increases an electroactive surface area of graphitic materials [19]. An increase in resonance frequency of QCM signifies that mass is removed from the sensor. If a physical surface area of the electrode is eroded, then it would explain reduction in recorded currents.

The layers were further investigated by simultaneously applying short potential pulses under the flow of $100 \mathrm{mM}$ $\mathrm{KCl}$ electrolyte. Duration of each voltage pulse was $10 \mathrm{~s}$ (Fig. 2c and d). During pulses of $0.1 \mathrm{~V}, 0.2 \mathrm{~V}, 0.3 \mathrm{~V}, 0.4 \mathrm{~V}$, $0.5 \mathrm{~V}, 0.6 \mathrm{~V}, 0.7 \mathrm{~V}, 0.8 \mathrm{~V}$, and $0.9 \mathrm{~V}$, frequency and dissipation did not deviate from the established baselines (area $\boldsymbol{a}$ on Fig. 2c). Currents recorded had values below $0.05 \mathrm{~mA}$, except from the last $2 \mathrm{~s}$ of $0.9 \mathrm{~V}$ pulse when the current increased to $\sim 0.06 \mathrm{~mA}$ (Fig. 2d). When $1.0 \mathrm{~V}$ pulse was applied, it caused shifts of frequency and dissipation (spike $\boldsymbol{b}$ in Fig. 2c). A rapid decrease of frequency is followed by an increase (area $c$ in Fig. 2c), but the dissipation continues to increase after the initial offset. The $1.1 \mathrm{~V}$ pulse was applied before equilibration of the process was achieved (spike $\boldsymbol{d}$ in Fig. 2c). This pulse caused a similar pattern (area $\boldsymbol{e}$ in Fig. 2c), where we attribute a decrease in frequency to restructuring of adsorbate water layers caused by their interactions with graphene electrode, and a following increaseto a partial loss of graphene layer (see also Fig. 3 and its discussion). Without further pulses applied, the system spontaneously reached a new equilibrium state with a frequency value above the baseline but increased dissipation (area $f$ in
Fig. 2c), similarly to a state caused by linear sweep-related restructuring. A positive frequency shift means desorption of the material from the sensor. Time between start of pulses 2 and 4 and local minimums of frequency in areas 3 and 5 is around $50 \mathrm{~s}-\mathrm{it}$ is clear that a change in frequency shift directionality is not related to an end of a voltage pulse. Levels of currents recorded for $1.0 \mathrm{~V}$ and $1.1 \mathrm{~V}$ are significantly higher than for previous sweeps (Fig. 2d). Total charge passed during $1.0 \mathrm{~V}$ pulse is $1.98 \mathrm{mC}$ and during $1.1 \mathrm{~V}$ pulse $-9.21 \mathrm{mC}$. We attribute these increased currents to anodization of graphene. During that process, most of the charge is consumed by oxygen-involving reactions [20]. Oxygen oxidation reaction-oxidation of water molecules to molecular oxygen, starts at potentials around $1 \mathrm{~V}$ vs $\mathrm{Ag} /$ $\mathrm{AgCl}$ on carbon materials [21-23] and leads to a variety of oxygenated groups produced on graphitic surface [24]. This would lead to a mass increase of the sensor layer. However, we suggest that an overall response to a layer oxidation is dominated by the layer fracturing and detachment of graphene sheds, as implied by the mass decrease, the decrease of the redox current magnitude (Fig. 2b), and no change in peak-to-peak separation of the redox current (Fig. 2b). Further inspection with the Raman spectra mapping confirmed this suggestion.

\section{Surface investigation with Raman spectroscopy}

Figure $3 \mathrm{a}$ and $\mathrm{b}$ depicts components of the recorded Raman spectra of a sensor before and after its electrochemical treatment. After the transfer (Fig. 3a), a layer has a typical CVD graphene spectra, which can be separated into two components: an ideal graphene spectra with $I_{\mathrm{G}^{\prime}}$ and $I_{\mathrm{G}}$ peaks on 2700 and $1600 \mathrm{~cm}^{-1}[25,26]$ and their ratio
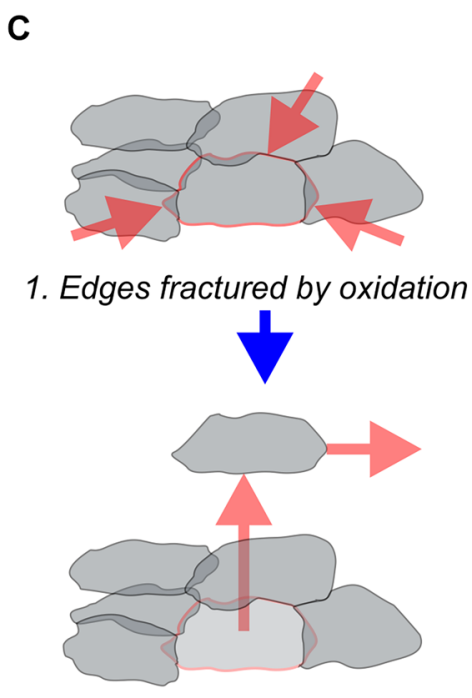

2. Sheds removed by the flow
Fig. 3 Raman spectra maps of graphene layer before (a) and after (b) its electrochemical oxidation. c Proposed mechanism of the layer degradation
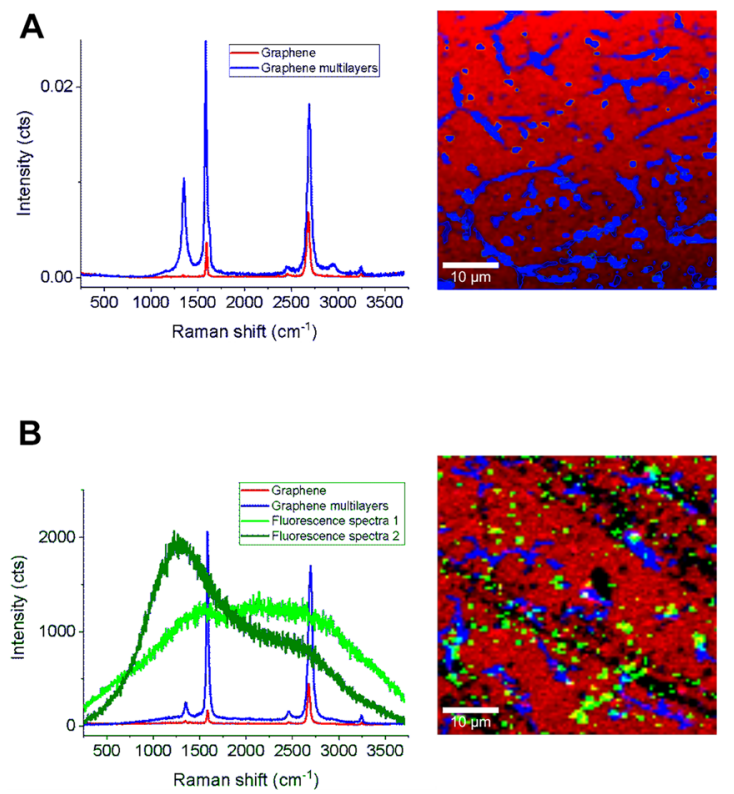
$I_{\mathrm{G}^{\prime}} / I_{\mathrm{G}}>1$ (red spectra and areas on Fig. 3a), and areas of folded layer with an additional disorder-induced $I_{\mathrm{D}}$ peak at $1300 \mathrm{~cm}^{-1}$ an intensity ratio $I_{\mathrm{G}^{\prime}} / I_{\mathrm{G}}<1$ (blue spectra and areas on Fig. 3a). These folds may be accountable for an increased layer mass measured with QCM after the transfer. After oxidative treatment, the most noticeable are two changes: appearance of bare areas without graphene (black areas on the map in Fig. 3b), and huge fluorescence signal (green spectra and areas in Fig. 3b). Fluorescence may arise from two components of a post-anodization system. First are clusters of amorphous carbon formed by re-adhered graphene layer sheds [27]. Second is residues of the redox probe 1,1'-Ferrocenedimethanol. Coupling of ferrocene (an organic $\pi$-system) compounds to a graphitic lattice was observed for carbon materials [28].

We suggest that applied potentials cause micro-fracturing of the graphene due to a strain inflicted by $\mathrm{sp}^{3}$-bonded carbons of oxygenated groups on $\mathrm{sp}^{2}$ lattice of graphene. These groups are not evenly distributed through an electrode basal plane, but mostly are lined along the edges of grains that appear during growth or cracks that appear during wet transfer [29, 30]. That leads to detachment of pieces. Anodization of highly ordered pyrolytic graphene results in increase of surface roughness [19] and subsequent fracturing [20, 31]. Similar process would explain our observations. Then these fractures cause detachment of graphene sheds from an oscillating substrate, which are then carried away by the flow with some of the sheds re-adhering to the surface (Fig. 3c). Increased roughness of the surface would account for increased dissipation recorded by QCM; however, additional changes of adsorbate layers may have a part in that. Wettability and water viscosity of the contact layer are different for hydrophobic and hydrophilic surfaces [32]. When an area of graphene is substituted by underlying hydrophilic $\mathrm{SiO}_{2}$, restructuring of adsorbate layers will occur.

\section{Conclusions}

Quartz crystal microbalance method provided insights in an ideality of large-scale CVD graphene layers created via a wet transfer method. It was shown that the transferred CVD graphene layer has higher mass than expected from an ideal abstract layer, presumably due to corrugations of the layer. Oxidation of the layer by applied high potential did not happen uniformly over the basal plane, but rather destroyed the layer integrity at the weak spots, leaving the rest of the surface unchanged. Degradation of the layer by potentials of over $0.9 \mathrm{~V}$ (vs $\mathrm{Ag} / \mathrm{AgCl}$ ) was directly recorded by simultaneous QCM monitoring.
Funding Open Access funding enabled and organized by ProjektDEAL.

Data availability The datasets generated during and/or analyzed during the current study are available from the corresponding authors on reasonable request.

\section{Declarations}

Conflict of interest On the behalf of all authors, corresponding authors state that there is no conflict of interest.

Open Access This article is licensed under a Creative Commons Attribution 4.0 International License, which permits use, sharing, adaptation, distribution and reproduction in any medium or format, as long as you give appropriate credit to the original author(s) and the source, provide a link to the Creative Commons licence, and indicate if changes were made. The images or other third party material in this article are included in the article's Creative Commons licence, unless indicated otherwise in a credit line to the material. If material is not included in the article's Creative Commons licence and your intended use is not permitted by statutory regulation or exceeds the permitted use, you will need to obtain permission directly from the copyright holder. To view a copy of this licence, visit http://creativecommons.org/licenses/by/4.0/.

\section{References}

1. X. Zhang, Q. Jing, S. Ao, G.F. Schneider, D. Kireev, Z. Zhang, W. Fu, Small 16(15), 1902820 (2020)

2. D. Kireev, A. Offenhäusser, 2D Mater. 5(4), 042004 (2018)

3. S. Taniselass, M.K.M. Arshad, S.C.B. Gopinath, Biosens. Bioelectron. 130, 276-292 (2019)

4. Y. Shao, J. Wang, H. Wu, J. Liu, I.A. Aksay, Y. Lin, Electroanalysis 22(10), 1027-1036 (2010)

5. W. Fu, C. Nef, A. Tarasov, M. Wipf, R. Stoop, O. Knopfmacher, M. Weiss, M. Calame, C. Schönenberger, Nanoscale 5(24), 12104-12110 (2013)

6. L. Wang, Y. Zhang, A. Wu, G. Wei, Anal. Chim. Acta 985, 24-40 (2017)

7. O.O. Kapitanova, E.Y. Kataev, D.Y. Usachov, A.P. Sirotina, A.I. Belova, H. Sezen, M. Amati, M. Al-Hada, L. Gregoratti, A. Barinov, H.D. Cho, T.W. Kang, G.N. Panin, D. Vyalikh, D.M. Itkis, L.V. Yashina, J. Phys. Chem. C 121(50), 27915-27922 (2017)

8. Y. Mulyana, M. Uenuma, Y. Ishikawa, Y. Uraoka, J. Phys. Chem. C 118(47), 27372-27381 (2014)

9. T. Kuila, S. Bose, A.K. Mishra, P. Khanra, N.H. Kim, J.H. Lee, Prog. Mater Sci. 57(7), 1061-1105 (2012)

10. M.Y. Vagin, A.N. Sekretaryova, A. Håkansson, T. Iakimov, I.G. Ivanov, M. Syväjärvi, R. Yakimova, I. Lundström, M. Eriksson, ChemElectroChem 6(14), 3791-3796 (2019)

11. F. Höök, M. Rodahl, P. Brzezinski, B. Kasemo, Langmuir 14(4), 729-734 (1998)

12. R.J. Dolleman, M. Hsu, S. Vollebregt, J.E. Sader, H.S.J. van der Zant, P.G. Steeneken, M.K. Ghatkesar, Appl. Phys. Lett. 115(5), (2019)

13. S. Deng, V. Berry, Mater. Today 19(4), 197-212 (2016)

14. W. Li, C. Tan, M.A. Lowe, H.D. Abruña, D.C. Ralph, ACS Nano 5(3), 2264-2270 (2011)

15. W. Zhu, T. Low, V. Perebeinos, A.A. Bol, Y. Zhu, H. Yan, J. Tersoff, P. Avouris, Nano Lett. 12(7), 3431-3436 (2012)

16. G. Imamura, K. Saiki, ACS Appl. Mater. Interfaces. 7(4), 24392443 (2015) 
17. J.D. Wood, G.P. Doidge, E.A. Carrion, J.C. Koepke, J.A. Kaitz, I. Datye, A. Behnam, J. Hewaparakrama, B. Aruin, Y. Chen, Nanotechnology 26(5), (2015)

18. Y.-C. Lin, C.-C. Lu, C.-H. Yeh, C. Jin, K. Suenaga, P.-W. Chiu, Nano Lett. 12(1), 414-419 (2012)

19. C.X. Lim, H.Y. Hoh, P.K. Ang, K.P. Loh, Anal. Chem. 82(17), 7387-7393 (2010)

20. R. Bowling, R.T. Packard, R.L. McCreery, Langmuir 5(3), 683688 (1989)

21. N. Daems, X. Sheng, I.F.J. Vankelecom, P.P. Pescarmona, J. Mater. Chem. A 2(12), 4085-4110 (2014)

22. Y. Cheng, S.P. Jiang, Prog. Nat. Sci.: Mater. Int. 25(6), 545-553 (2015)

23. C. Hu, L. Dai, Adv. Mater. 29(9), 1604942 (2017)

24. Y. Yi, G. Weinberg, M. Prenzel, M. Greiner, S. Heumann, S. Becker, R. Schlögl, Catal. Today 295, 32-40 (2017)

25. I. Calizo, A.A. Balandin, W. Bao, F. Miao, C.N. Lau, Nano Lett. 7(9), 2645-2649 (2007)

26. A.C. Ferrari, J.C. Meyer, V. Scardaci, C. Casiraghi, M. Lazzeri, F. Mauri, S. Piscanec, D. Jiang, K.S. Novoselov, S. Roth, A.K. Geim, Phys. Rev. Lett. 97(18), (2006)
27. G.A. Rechtsteiner, C. Felix, A.K. Ott, O. Hampe, R.P. Van Duyne, M.F. Jarrold, K. Raghavachari, J. Phys. Chem. A 105(13), 3029_ $3033(2001)$

28. X.-J. Huang, H.-S. Im, D.-H. Lee, H.-S. Kim, Y.-K. Choi, J. Phys. Chem. C 111(3), 1200-1206 (2007)

29. J. Lee, Y. Kim, H.-J. Shin, C. Lee, D. Lee, S. Lee, C.-Y. Moon, S.C. Lee, S.J. Kim, J.H. Ji, H.S. Yoon, S.C. Jun, ACS Appl. Mater. Interfaces. 6(15), 12588-12593 (2014)

30. X. Li, W. Cai, J. An, S. Kim, J. Nah, D. Yang, R. Piner, A. Velamakanni, I. Jung, E. Tutuc, S.K. Banerjee, L. Colombo, R.S. Ruoff, Science 324(5932), 1312-1314 (2009)

31. A. Usikov, M. Puzyk, S. Novikov, I. Barash, O. Medvedev, A. Roenkov, A. Goryachkin, S.P. Lebedev, A. Zubov, Y. Makarov, presented at the Key Engineering Materials, 2019 (unpublished)

32. C. Sendner, D. Horinek, L. Bocquet, R.R. Netz, Langmuir 25(18), 10768-10781 (2009) 